- The study results indicate a definite association between periodontal disease and acute myocardial infarction, a finding of significant public health importance.

- Dental infections by way of decayed teeth are also found to be significantly associated with acute myocardial infarction.

- Although stressing the relation between dental infections and acute myocardial infarction, the importance of serum lipids in the occurrence of coronary heart disease is also shown.

\title{
Periodontal disease as a risk factor for acute myocardial infarction. A case-control study in Goans highlighting a review of the literature
}

\author{
S. Kaisare, ${ }^{1}$ J. Rao ${ }^{2}$ and N. Dubashi ${ }^{3}$
}

Objectives The aim of the present study was to investigate the possible association between periodontal health and acute myocardial infarction (AMI) in a case-control design.

Materials and methods A total of 500 patients, 250 with AMI and 250 with coronary heart disease (CHD) were included in this study. The patients in the AMI group were admitted in the department of Medicine, Goa Medical College and Hospital, Bambolim-Goa because of AMI. The patients in the CHD group had no documented history of recent acute coronary events. Medical history was taken and data on serum lipid values, decayed teeth, missing teeth, filled teeth, probing depth (PD), simplified oral hygiene index (OHI-S) and bleeding on probing (BOP) were recorded. Sample proportions were compared by Pearson's chi-square test and quantitative variables with Student's t-test. The relation of clinical parameters and conventional risk factors with AMI was assessed with multivariate logistic regression analysis. Results All the serum lipids and dental parameters were statistically different between AMI and CHD groups ( $p<0.05)$. Logistic regression analysis showed that serum lipids, number of decayed teeth, mean $P D$, percentage of sites with $B O P$, and oral hygiene were significantly associated with AMI $(p<0.05)$.

Conclusion The results of this study indicate that periodontal disease may be associated with AMI. We propose that prospective randomised studies are needed to determine whether periodontal disease is a risk factor in the occurrence of AMI.

'Department of Periodontics, Goa Dental College and Hospital, Bambolim, Goa403206, India; ${ }^{2}$ Professor and Head, Department of Periodontics, ${ }^{3}$ Professor and Head, Department of General Medicine, Goa Dental College and Hospital, Bambolim, Goa-403206, India

${ }^{*}$ Correspondence to: Dr Sumeet Kaisare

Email:sumeetkaisare@rediffmail.com

Online article number E5

Refereed Paper - accepted 3 January 2007

DOI: $10.1038 /$ bdj.2007.582

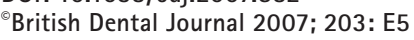

INTRODUCTION

Coronary heart disease (CHD) is the leading cause of adult mortality and morbidity throughout the world. The development of CHD can result from genetic and several environmental risk factors such as age, abnormal serum lipids, diabetes, smoking, and hypertension. ${ }^{1-3}$ These well-known risk factors independently or in combination are involved in both acute myocardial infarction (AMI) and atherosclerosis. ${ }^{4,5}$ Recent data have shown that viral and bacterial infections may also contribute to acute thromboembolic events in susceptible people. ${ }^{6,7}$

Periodontal diseases are a group of inflammatory diseases in which bacteria and their by-products are the principal aetiologic agents. ${ }^{8}$ The first indication of association between dental disease and atherosclerosis was given in $1963 .{ }^{9}$ Since then, there is growing evidence that poor dental health, especially the presence of periodontal disease, increases the risk of occurrence of CHD. ${ }^{10,11}$

Studies conducted on different populations have suggested that atherosclerosis and the occurrence of AMI could be linked with chronic oral infections. ${ }^{12-14}$ These studies confirm the observation that heart disease is the most commonly found systemic condition in patients with periodontal disease. ${ }^{15}$ Moreover, the literature has also highlighted substantial evidence indicating the presence of gram-negative periodontal pathogens in atheromatous plaques. ${ }^{16}$

Since periodontal diseases and heart diseases are common, quantifying their association is of significant public health importance. The interpretation of the reported associations is difficult. On the one hand, the associations could be interpreted as causal, ${ }^{10,12-14,17-34}$ which could imply, as has been suggested, that reducing periodontal disease with interventions may have the additional benefit of reducing the risk of cardiovascular disease. On the other hand, these data could be interpreted as being artifacts, that is, the result of biases caused by confounding. Since periodontitis and myocardial disease share common risk factors, such as increasing age, smoking, 
Table 1 Means and proportions of personal characteristics in patients with $\mathrm{AMI}$ and $\mathrm{CHD}$

\begin{tabular}{|c|c|c|c|}
\hline & AMI & CHD & $\mathrm{p}$ \\
\hline Number of patients & 250 & 250 & - \\
\hline $\begin{array}{l}\text { Age (years; } \\
\text { mean } \pm \text { SD) }\end{array}$ & $55.5 \pm 9.8$ & $55.4 \pm 8.2$ & 0.856 \\
\hline $\begin{array}{l}\text { Gender distribution } \\
\text { (male/female) }\end{array}$ & $143 / 107$ & $144 / 106$ & 0.928 \\
\hline $\begin{array}{l}\text { Educational } \\
\text { qualifications } \\
\text { (uneducated/primary/ } \\
\text { secondary/higher } \\
\text { secondary and above) }\end{array}$ & $50 / 43 / 61 / 96$ & $42 / 45 / 62 / 101$ & 0.083 \\
\hline $\begin{array}{l}\text { Occupation } \\
\text { (employed/ } \\
\text { unemployed) }\end{array}$ & $106 / 144$ & $122 / 128$ & 0.151 \\
\hline $\begin{array}{l}\text { Marital status } \\
\text { (married/unmarried) }\end{array}$ & $239 / 11$ & $246 / 4$ & 0.066 \\
\hline $\mathrm{SD}=$ Standard deviation & & & \\
\hline
\end{tabular}

\begin{tabular}{|c|c|c|c|}
\hline & AMI & CHD & $p$ \\
\hline Number of patients & 250 & 250 & - \\
\hline $\begin{array}{l}\text { Diabetic status } \\
\text { (diabetic/ } \\
\text { non-diabetic) }\end{array}$ & $99 / 151$ & $68 / 182$ & $0.03^{*}$ \\
\hline $\begin{array}{l}\text { Hypertensive status } \\
\text { (hypertensive/ } \\
\text { non-hypertensive) }\end{array}$ & 189/61 & $181 / 69$ & 0.415 \\
\hline $\begin{array}{l}\text { Smoking status } \\
\text { (current/former/ } \\
\text { non-smoker) }\end{array}$ & $54 / 62 / 134$ & $39 / 47 / 164$ & $0.023^{*}$ \\
\hline $\begin{array}{l}\text { Serum total } \\
\text { cholesterol } \\
(\text { mean } \pm S D)\end{array}$ & $250 \pm 222.2$ & $200.6 \pm 25.7$ & $0.00^{\#}$ \\
\hline $\begin{array}{l}\text { Serum LDL cholesterol } \\
(\text { mean } \pm \text { SD) }\end{array}$ & $156.7 \pm 24.3$ & $135.5 \pm 18.6$ & $0.00^{\#}$ \\
\hline $\begin{array}{l}\text { Serum HDL choles- } \\
\text { terol (mean } \pm \text { SD) }\end{array}$ & $39.9 \pm 4.7$ & $44.7 \pm 6.3$ & $0.00^{\#}$ \\
\hline $\begin{array}{l}\text { Serum triglyceride } \\
\text { level (mean } \pm \text { SD) }\end{array}$ & $174.8 \pm 65.3$ & $130.7 \pm 35.4$ & $0.00^{\#}$ \\
\hline
\end{tabular}

stress, and socioeconomic status, the potential for confounding is substantial. Incomplete adjustment for these factors may be responsible for the observed weak associations. ${ }^{9,11,35-40}$

The purpose of the present study was to investigate the possible association between periodontal health and CHD in a case-control study.

\section{MATERIALS AND METHODS}

This study was designed in the Department of Periodontics, Goa Dental College and Hospital, Bambolim-Goa and conducted in the coronary care unit (CCU), intermediary coronary care unit (ICCU) and the outpatient department (OPD) of medicine, Goa Medical College and Hospital, Bambolim-Goa.

Informed consent of the patients was obtained prior to the examination. A case-control design was chosen to include a total of 500 ethnic Goan patients (age range from 29 to 85 years; 287 males and 213 females). Of these, 250 patients had acute myocardial infarction (AMI) and 250 had coronary heart disease (CHD).

The AMI group included patients admitted to the CCU or ICCU of the Department of Medicine, depending on the severity of their condition. AMI was verified by typical changes in the electrocardiogram (ECG) and elevation of serum enzymes (serum glutamic-oxaloacetic transaminase [SGOT], creatinine phosphokinase [CPK] and CPK MB-isoenzyme) together with or without chest discomfort consistent with AMI. The patients in the second group (CHD) included those from the OPD of medicine who had been documented to have CHD with no history of recent acute coronary events (four weeks).

\section{Exclusion criteria}

Those patients who were labelled unfit by the concerned cardiologist due to their anticoagulant status or the severity of the condition were excluded from the study. Moreover, the patients who were chosen to be a part of AMI group were excluded from being considered in the CHD group during their follow-up.

\section{Medical history}

After obtaining the institutional approval and consent of the subjects, a study questionnaire was used to review the patients' age, gender, address, educational qualifications, occupation, marital status, past dental history, diabetic and hypertensive status, and smoking status. Data on serum total cholesterol, triglyceride, high density lipoprotein (HDL) cholesterol and low density lipoprotein (LDL) cholesterol were recorded.

Educational qualifications were classified into four groups as follows:

1. Uneducated: individuals with no formal education (inclusive of those who had not completed primary education)

2. Primary: individuals who had completed primary education (up to Std IV)

3. Secondary: individuals who had completed secondary education (up to Std X)

4. Higher secondary and above: individuals who had completed higher secondary education (up to Std XII) and also those who had sought further education.

Occupation and marital status were categorised dichotomously as employed/unemployed and married/unmarried respectively. Similarly, diabetic and hypertensive status were 
also dichotomously recorded as diabetic/non-diabetic and hypertensive/non-hypertensive respectively.

Based on the criteria established by the Centers for Disease Control and Prevention (CDC), smokers were grouped as current, former and non-smokers. Current smokers smoked more than 100 cigarettes in their lifetime and were currently smoking; former smokers smoked more than 100 cigarettes in their lifetime and were not currently smoking, while non-smokers had not smoked more than 100 cigarettes in their lifetime.

\section{Dental examination}

AMI patients were clinically examined three to four days after admission to the CCU or ICCU, while the clinical examination of the CHD patients was carried out in the OPD. All the teeth inclusive of the third molars were studied and number of decayed teeth, number of missing teeth, number of filled teeth, mean probing depth (PD), simplified oral hygiene index (OHI$\mathrm{S}){ }^{41}$ and percentage sites with bleeding on probing (BOP) ${ }^{42}$ were recorded.

The probing depth was recorded with William's Periodontal Probe (HU-FRIEDY, USA). The probing sites examined were mesial, mid-buccal, distal and mid-palatal/lingual for all the teeth. Periodontal pocket bleeding index (PPBI) was used to calculate the percentage of sites with BOP.

\section{Statistical analysis}

Means and proportions for personal characteristics, major risk factors and clinical parameters were calculated for both the groups. The significance of any difference in means was tested by using Student's t-test, and the significance of any difference in proportions was tested by using Pearson's chi-square test. The variables which were statistically insignificant in univariate analysis were not considered for further analysis.

The relation of the independent variables with AMI (dependent variable) was assessed by using multivariate logistic regression analysis on subject-based data.

Statistical analysis was performed using SPSS software (version 10.5) and statistical significance was defined as $\mathrm{p}<0.05$.

\section{RESULTS}

Tables 1, 2 and 3 show the means ( \pm standard deviation [SD]) and proportions of the personal characteristics, risk factors and clinical parameters of both study groups. It is obvious from Table 1 that there was no statistically significant difference in the personal characteristics between the groups. However, as can be seen in Table 2, all the risk factors with the exception of hypertension were significantly higher among the AMI patients when compared to the CHD patients. Moreover, Table 3 reveals a statistically significant difference in all the clinical parameters examined between AMI and CHD groups, indicating a higher value for the AMI group.

The variables which were found to be statistically significant in univariate analysis were subjected to multivariate logistic regression analysis to evaluate their significance in the presence of confounding factors. Table 4 indicates the multivariate logistic regression analysis with risk factors and clinical parameters as independent variables and AMI as the dependent variable. This analysis indicated that HDL cholesterol, LDL cholesterol, triglycerides, number of decayed teeth, mean PD, percentage of sites with BOP, and oral hygiene were significantly associated with AMI ( $p<0.05)$.

Table 5 reveals the accuracy of the sample chosen for the study. It was found that the selection of the subjects for this study was $92.55 \%$ accurate.

\section{DISCUSSION}

Coronary heart disease (CHD) is forecast to be the most common cause of death globally, including India, by 2020. Causing over 3 million deaths in India every year, CHD is assuming the form of an epidemic.

The association between dental infections and CHD was first coined by MacKenzie and Mallard ${ }^{9}$ and is being thoroughly investigated. Although various mechanisms have been postulated to explain this link, ${ }^{43}$ it is not clear to what extent, if any, a relationship exists between the two diseases. Hence, we specifically carried out this case-control study wherein the periodontal status was evaluated in cases (patients with AMI) and controls (patients with CHD). Other case-control studies $^{9,12,19,21,27,28,32-34,36}$ considered healthy age- and sex-matched individuals as controls, unlike our study. However, this study design, which resembled the one by Emingil et al., ${ }^{24}$ ensured that the cases and controls had identical backgrounds that could eliminate some confounding factors in univariate analysis.

The present study supports the findings of various other authors ${ }^{10,12-14,17-34}$ who have found a relationship between periodontitis and cardiovascular disease. Unlike these studies, a few notable studies did not find any overall association between the two diseases..$^{9,11,35-40}$ It was found by these researchers that the association between the two diseases achieved statistical insignificance when considered in combination with other risk factors.

\begin{tabular}{|c|c|c|c|}
\hline & AMI & CHD & $\mathrm{p}$ \\
\hline Number of patients & 250 & 250 & - \\
\hline $\begin{array}{l}\text { Number of decayed } \\
\text { teeth (Mean } \pm \text { SD) }\end{array}$ & $4 \pm 3.7$ & $2.8 \pm 2.6$ & $0.00^{\#}$ \\
\hline $\begin{array}{l}\text { Number of missing } \\
\text { teeth }(\text { mean } \pm \text { SD) }\end{array}$ & $12 \pm 12$ & $7.5 \pm 10$ & $0.00^{\#}$ \\
\hline $\begin{array}{l}\text { Number of filled teeth } \\
\text { (mean } \pm \text { SD) }\end{array}$ & $2 \pm 3.1$ & $1.3 \pm 1.39$ & $0.006^{A}$ \\
\hline $\begin{array}{l}\text { Mean probing depth } \\
( \pm \text { SD })\end{array}$ & $6.1 \pm 1.98$ & $3.1 \pm 1.1$ & $0.00^{*}$ \\
\hline $\begin{array}{l}\text { Oral hygiene status } \\
\text { (poor/fair/good) }\end{array}$ & $127 / 65 / 4$ & $18 / 182 / 20$ & $0.00^{*}$ \\
\hline $\begin{array}{l}\text { Percentage of sites } \\
\text { with bleeding on } \\
\text { probing (mean } \pm \text { SD) }\end{array}$ & $34.3 \pm 8.8$ & $15.1 \pm 10.2$ & $0.00^{\#}$ \\
\hline
\end{tabular}




\begin{tabular}{|c|c|c|c|}
\hline $\begin{array}{l}\text { Percentage sites with } \\
\text { bleeding on probing }\end{array}$ & +0.072 & $0.000^{\#}$ & 1.075 \\
\hline Serum LDL cholesterol & +0.027 & $0.008^{\#}$ & 1.028 \\
\hline Serum HDL cholesterol & -0.142 & $0.000^{*}$ & 0.862 \\
\hline Serum triglyceride & +0.013 & $0.021^{\#}$ & 1.013 \\
\hline Oral hygiene status & - & $0.000^{*}$ & - \\
\hline Poor oral hygiene & +2.030 & $0.049^{*}$ & 7.618 \\
\hline Fair oral hygiene & -0.101 & 0.914 & 0.177 \\
\hline $\begin{array}{l}\text { Good oral hygiene } \\
\text { (ref) }\end{array}$ & - & - & 1 \\
\hline Constant & +2.341 & 0.29 & 10.401 \\
\hline \multicolumn{4}{|c|}{$\begin{array}{l}\text { Ref indicates reference group } \\
\text { *Statistically significant ( }<<0.05 \text {, Pearson's chi-square test) } \\
\text { "Statistically significant ( } p<0.05 \text {, Student's t-test) }\end{array}$} \\
\hline
\end{tabular}

In this study, the personal characteristics considered were age, sex, educational qualifications, occupation and marital status. All of these can independently serve as potential risk factors for CHD, ${ }^{44-47}$ however, we found no significant difference in these characters between the cases and controls. This is in agreement with Emingil et al. ${ }^{24}$ and could be explained by the study design.

The present study found no association of risk factors such as diabetes, hypertension and smoking with AMI. Our results agree with few other studies who failed to show any relationship between CHD and any of these risk factors. ${ }^{11-14}$ However, in this study, serum lipid levels were found to be significantly associated with AMI as computed by multivariate logistic regression analysis. Abnormal serum lipids have been reported to be significant risk factors for both atherosclerosis and infarction and our study is in agreement with this. ${ }^{4,5,48}$ As opposed to this, few others $^{13,14}$ have observed a lack of association between serum lipids and atherosclerosis.

It is worth appraising the fact that most of the above mentioned risk factors were found to be significantly more prevalent in the AMI group as compared to the CHD group in univariate analysis. This could be because of the absence of
Table 5 Evaluation of accuracy of the study sample

\begin{tabular}{l|l|l|l}
\hline \multirow{2}{*}{ Observed group } & \multicolumn{2}{|l|}{ Predicted group } & Percentage correct \\
\cline { 2 - 4 } & Cases & Controls & \\
\hline Cases & 185 & 16 & 92 \\
\hline Controls & 14 & 191 & 93.1 \\
\hline Overall percentage & - & - & 92.55 \\
\hline
\end{tabular}

confounding factors, and also due to counselling given to the CHD group pertaining to dietary intake and hazardous effects of smoking, most of whom were receiving medical treatment affecting blood lipid values. However, when this association was computed in the presence of other confounding factors using multivariate logistic regression analysis, it achieved statistical insignificance with the exception of serum lipids.

We analysed various clinical parameters to prove the correlation between dental infections and CHD. When the number of decayed teeth, number of missing teeth and number of filled teeth were assessed in univariate analysis, we found all these parameters to be significantly higher in the AMI group as compared to the CHD group, as has been shown by many studies. ${ }^{11,14,18,20,23,24,28,30,49}$ However, when these parameters were subjected to multivariate logistic regression analysis, only the number of decayed teeth was found to be associated with AMI. Similarly, Touminen et $a l .{ }^{40}$ in their very recent study reported that these associations between missing teeth, decayed teeth, filled teeth and CHD proved to be statistically insignificant when considered with other well-established risk factors for CHD. One interesting observation that could be noted at this point is that past dental history was not significantly different between the groups, indicating similar dental awareness in both the groups. In spite of this, the AMI group had significantly more decayed, filled and missing teeth as compared with the CHD group, which is a worthwhile point, strengthening the link between the two diseases.

In the present study, an association between poor periodontal health and AMI was found. Periodontal status was assessed by the mean probing depth (PD), oral hygiene status and percentage of sites with bleeding on probing (BOP). Radiographic estimation of the alveolar bone level could not be performed due to the severity of the medical condition of the patients and this could be considered theoretically as one of the weaknesses of this study.

The mean PD was found to be significantly higher in the AMI group than in the CHD group. Multivariate logistic regression analysis confirmed that this parameter significantly correlated with AMI when other risk factors were considered. A similar observation has been noted by many authors, ${ }^{22,24,27,30,31,33}$ however few others ${ }^{26,40}$ have reported no association between PD and CHD.

When oral hygiene status was tested, poor oral hygiene was significantly higher in the AMI group. In multivariate logistic regression analysis, a significant correlation was 
found between poor oral hygiene and AMI. Poor oral hygiene was found to be significantly associated with CHD in some studies, ${ }^{9,14,20}$ which is in agreement with our study. However, Tuominen et $a l .{ }^{40}$ have found no association between the two. The debris score of the simplified oral hygiene index (OHI-S) could have been falsely recorded high by us, as the patients in the AMI group were bound to have poor oral hygiene after their admission to the coronary care unit. However, calculus score would be a relatively stable parameter in the AMI group, as it takes two weeks for plaque to become mineralised into calculus. ${ }^{50}$ Hence, we computed calculus score separately and found precisely the same result that was obtained with OHI-S score.

Gingival bleeding, an indicator of gingival inflammation, can be clinically observed approximately one week after cessation of oral hygiene measures. ${ }^{51}$ We found that gingival bleeding was significantly higher in the AMI group when compared with the CHD group. This was possibly due to poor oral hygiene and gingival inflammation in the AMI group before the infarct, as the patients were examined within three to four days of their admission. This association was confirmed in the multivariate logistic regression analysis. Gingival bleeding is one of the definite risk predictor/markers for periodontal disease progression, hence we believe that this is one of the most important positive findings noted in this study that is relevant from a clinical point of view. This observation is in agreement with various other studies, ${ }^{14,24,26,29,31}$ however, Persson et al. ${ }^{27}$ did not agree with this observation.

With the amount of literature that has accumulated, it can be presumed that an association between periodontal disease and CHD is relatively common in different populations. The present study, being a case-control design, provides further evidence of the role of periodontal disease in cardiovascular disease. However, we agree with Loesche et al. ${ }^{14}$ that such studies cannot be generalised to an entire population. Larger and better-controlled studies involving socially homogeneous populations and measuring specific periodontal pathogens are required to identify a definite association between periodontal disease and the risk of CHD. Randomised clinical trials are of utmost importance for confirming a causal association. One such trial is being attempted by Grossi et al., ${ }^{52}$ which may provide a breakthrough in the field of periodontal medicine.

\section{CONCLUSION}

The results of this study indicate an association between periodontal disease and acute myocardial infarction. Moreover, the accumulation of epidemiologic, in vitro, clinical and animal evidence suggests that periodontal infection may be a contributing risk factor for heart disease. However, legitimate concerns have arisen about the nature of this relationship.

Since even a moderate risk contributed by periodontal disease to heart disease could lead to significant morbidity and mortality, it is imperative that further studies be conducted to evaluate this relationship. To strengthen this association, we would like to recommend a randomised interventional study, which would aim at a possible clinically meaningful reduction in heart disease resulting from the prevention or treatment of periodontal disease.

The authors wish to express their gratitude towards all the residents and paramedical staff of the Department of Medicine, Goa Medical College and
Hospital, Bambolim-Goa for helping us with the study. Our special thanks to $\operatorname{Dr}$ M. S. Kulkarni for carrying out the statistical analysis. Lastly, we would like to acknowledge all the patients examined by us without whom this study would not have been possible.

1. Fuster V, Badimon L, Badimon J J, Chesebro J H. The pathogenesis of coronary artery disease and the acute coronary syndromes [part 1]. N Eng/ J Med 1992; 326: $242-250$.

2. Fuster $V$, Badimon L, Badimon J J, Chesebro J H. The pathogenesis of coronary artery disease and the acute coronary syndromes [part 2]. N Engl J Med 1992; 326: $310-318$.

3. Hegele R A. The pathogenesis of atherosclerosis. Clin Chim Acta 1996; 246: 21-38.

4. Kauppinen R, Nikkila E A. Serum lipoproteins in patients with myocardial infarction. Atherosclerosis 1988; 74: 65-74.

5. Anderson K M. Castelli W P, Levy D. Cholesterol and mortality. 30 years of follow-up from the Framingham study. J Am Med Assoc 1987; 257: 2176-2180.

6. Mattila K J, Valtonen V V, Nieminen M S, Asikainen S. Role of infection as a risk factor for atherosclerosis, myocardial infarction and stroke. Clin Infect Dis 1998; 26: 719-734

7. Mattila K J. Viral and bacterial infections in patients with acute myocardial infarction. J Intern Med 1989; 225: 293-296.

8. Listgarten M A. Nature of periodontal diseases: pathogenic mechanisms. J Periodont Res 1987; 22: 172-178.

9. Mackenzie R S, Millard H D. Interrelated effects of diabetes, arteriosclerosis and calculus on alveolar bone loss. J Am Dent Assoc 1963; 66: 192-198.

10. Beck J, Garcia R, Heiss G, Vokonas P S, Offenbacher S. Periodontal disease and cardiovascular disease. J Periodontol 1996; 67: 1123-1137.

11. Joshipura K J, Rimm E B, Douglass C W, Trichopoulos D, Ascherio A, Willett W C. Poor oral health and coronary heart disease. J Dent Res 1996; 75: 1631-1636.

12. Mattila K J, Nieminen M S, Valtonen V V et al. Association between dental health and acute myocardial infarction. Br Med J 1989; 298: 779-781.

13. Mattila K J, Valle M S, Nieminen M S, Valtonen V V, Hietaniemi K L. Dental infections and coronary atherosclerosis. Atherosclerosis 1993; 103: 205-211.

14. Loesche W J, Schork A, Terpenning M S, Chen Y M, Dominguez B L, Grossman N. Assessing the relationship between dental disease and coronary heart disease in elderly U.S. Veterans. J Am Dent Assoc 1998; 129: 301-311.

15. Nery E B, Meister F, Ellinger R F, Eslami A, McNamara T J. Prevalence of medical problems in periodontal patients obtained from three different populations. J Periodontol 1987; 58: 564-568.

16. Haraszthy V I, Zambon J J, Trevisan M, Zeid M, Genco R J. Identification of periodontal pathogens in atheromatous plaques. J Periodonto/ 2000; 71: 1554-1560.

17. Mattila K J, Valtonen $V V_{\text {, Nieminen }} M$, Huttunen J K. Dental infection and the risk of new coronary events: prospective study of patients with documented coronary artery disease. Clin Infect Dis 1995; 20: 588-592.

18. Paunio K, Impivaara 0, Tiekso J, Maki J. Missing teeth and ischaemic heart disease in men aged 45-64 years. Eur Heart J 1993; 14: 54-56.

19. Kweider M, Lowe G D, Murray G D, Kinane D F, McGowan D A. Dental disease, fibrinogen and white cell count; links with myocardial infarction? Scott Med J 1993; 38: 73-74.

20. DeStefano F, Anda R F, Kahn H S, Williamson D F, Russell C M. Dental disease and risk of coronary heart disease and mortality. Br Med J 1993; 306: 688-691.

21. Genco R J, Wu T, Grossi S, Faulkner K, Zambon J J, Trevisan M. Periodontal microflora related to the risk of myocardial infarction. A case-control study (abstract 2811). J Dent Res 1999; 78 (Spec Iss): 457.

22. Arbes S J, Slade G D, Beck J D. Association between extent of periodontal attachment loss and self-reported history of heart attack: an analysis of NHANES III data. J Dent Res 1999; 78: 1777-1782.

23. Morrison H I, Ellison L F, Taylor G W. Periodontal disease and risk of fatal coronary heart and cerebrovascular diseases. J Cardiovasc Risk 1999; 6: 7-11.

24. Emingil G, Buduneli $E$, Aliyev A, Akilli A, Atilla G. Association between periodontal disease and acute myocardial inafrction. J Periodontol 2000; 71: 1882-1886.

25. Jansson L, Lavstedt $\mathrm{S}$, Frithiof $\mathrm{L}$, Theobald $\mathrm{H}$. Relationship between oral health and mortality in cardiovascular diseases. J Clin Periodontol 2001; 28: 762-768.

26. Buhlin K, Gustafsson A, Hakansson J. Oral health and cardiovascular disease in Sweden. J Clin Periodontol 2002: 29: 254-259.

27. Persson R G, Ohlsson O, Pettersson T, Renvert S. Chronic periodontitis, a significant relationship with acute myocardial infarction. Eur Heart $J$ 2003; 24: $2108-2115$.

28. Meurman J H, Qvarnstrom M, Janket S J, Nuutinen P. Oral health and health behavior in patients referred for open-heart surgery. Oral Surg Oral Med Oral Pathol Oral Radiol Endod 2003; 95: 300-307.

29. Buhlin K, Gustafsson A, Hakansson J, Klinge B. Self-reported oral health, dental care habits and cardiovascular disease in an adult Swedish population. Oral Health Prev Dent 2003; 1: 291-299.

30. Elter J R, Champagne C M, Offenbacher S, Beck J D. Relationship of periodontal disease and tooth loss to prevalence of coronary heart disease. J Periodontol 2004; 75: 782-790.

31. Shimazaki Y, Saito T, Kiyohara Y, Kato I, Kubo M, lida M. Relationship between electrocardiographic abnormalities and periodontal disease: the Hiyasama study. J Periodontol 2004; 75: 791-797.

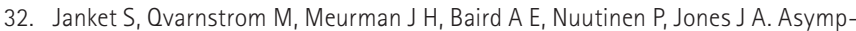
tomatic dental score and prevalent coronary heart disease. Circulation 2004; 109: 1095-1100. 
33. Cueto A, Mesa F, Bravo M, Ocana-Riola R. Periodontitis as a risk factor for acute myocardial infarction. A case-control study of Spanish adults. J Periodont Res 2005; 40: 36-42

34. Dogan B, Buduneli E, Emingil $G$ et al. Characteristics of periodontal microflora in acute myocardial infarction. J Periodonto/ 2005; 76: 740-748.

35. Hujoel P, Drangsholt M, Spiekerman C, DeRouen T. Periodontal disease and coronary heart disease risk. J Am Med Assoc 2000; 284: 1406-1410.

36. Mattila K J, Asikainen S, Wolf J, Jousimies S H, Valtonen V, Nieminen M. Age, dental infections and coronary heart disease. J Dent Res 2000; 79: 756-760.

37. Howell T H, Ridker P M, Ajani U A, Hennekens C H, Christen W G. Periodontal disease and risk of subsequent cardiovascular disease in U.S. male physicians. J Am Coll Cardiol 2001; 37: 445-450.

38. Hujoel P, Drangsholt M, Spiekerman C, DeRouen T. Examining the link between coronary heart disease and the elimination of chronic dental infections. J Am Dent Assoc 2001; 132: 883-889.

39. Hujoel P, Drangsholt M, Spiekerman C, DeRouen T. Pre-existing cardiovascular disease and periodontitis: a follow-up study. J Dent Res 2002; 81: 186-191.

40. Tuominen R, Reunanen A, Paunio M, Paunio R, Aromaa A. Oral health indicators poorly predict coronary heart disease deaths. J Dent Res 2003; 82: 713-718.

41. Peter S. Plaque control. In Peter S (ed) Essentials of preventive and community dentistry. 1st ed. pp 352-369. New Delhi: Arya Publishing, 2000.

42. Geerts S, Legrand V, Charpentier J, Albert A, Rompen E H. Further evidence of the association between periodontal conditions and coronary artery disease. J Periodontol 2004; 75: 1274-1280.

43. Seymour R A, Preshaw P M, Thomason J M, Ellis J S, Steele J G. Cardiovascular diseases and periodontology. J Clin Periodontol 2003; 30: 279-292.

44. Schoen F J, Cotran R S. The blood vessels. In Kumar V, Robbins S L (eds) Robbins basic pathology. 7th ed. pp 325-360. New Delhi: Elsevier, 2003.

45. Selwyn A, Braunwald E. Ischemic heart disease. In Kasper D L, Braunwald E, Fauci A S, Hauser S L, Longo D L, Jameson J L (eds) Harrison's principles of internal medicine. 16th ed. pp 1434-1444. New York: McGraw-Hill Professional, 2005.

46. Fiscella K, Franks P. Should years of schooling be used to guide treatment of coronary risk factors? Ann Fam Med 2004; 2: 469-473.

47. Weiss N S. Marital status and risk factors for coronary heart disease. The United States health examination survey of adults. Br J Prev Soc Med 1973; 27: 41-43.

48. Nobili A, D'Avanzo B, Santoro L, Ventura G, Todesco P, La Vecchia C. Serum cholesterol and acute myocardial infarction: a case-control study from the GISSI-2 trial. Br Heart J 1994; 71: 468-473.

49. Ahlqwist $M$, Bengtsson $C$, Lapidus $L$. Number of amalgam fillings in relation to cardiovascular disease, diabetes, cancer and early death in Swedish women. Community Dent Oral Epidemiol 1993; 21: 40-44.

50. Lang N, Mombelli A. Dental plaque and calculus. In Lindhe J, Karring T, Lang N (eds) Clinical periodontology and implant dentistry. 4th ed. pp 81-105. Copenhagen: Munksgaard, 2003

51. Kinane D F, Lindhe J. Pathogenesis of periodontitis. In Lindhe J, Karring T, Lang N (eds) Clinical periodontology and implant dentistry. 3rd ed. pp 189-225. Copenhagen: Munksgaard, 1997.

52. ClinicalTrials.gov. Periodontitis and cardiovascular events or 'PAVE' NCT00066053. http://www. clinicaltrials.gov/ct/show/NCT00066053? order $=30$. Accessed 21 August 2005. 